\title{
El riesgo cardiovascular en el desarrollo y prevención de Alzheimer y otras demencias. ¿Quién le teme a Alois Alzheimer?
}

Enrique Sánchez Delgado

Director de Educación Médica, Hospital Metropolitano Vivian Pellas, Managua, Nicaragua. Correo electrónico: esanchez@ metropolitano.com.ni

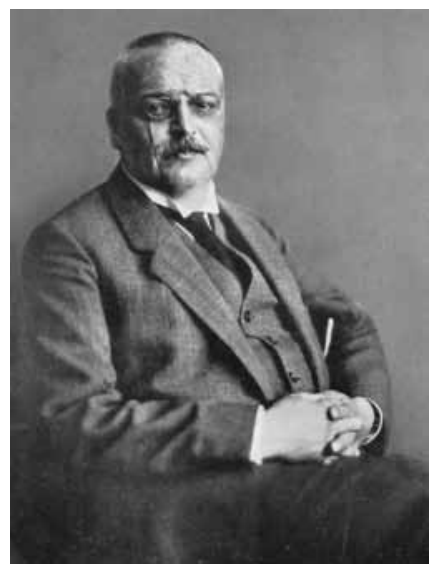

Foto del Dr. Alois Alzheimer
La demencia, con su temida pérdida de la memoria y alteraciones de la personalidad y la conducta, puede llegar alguna vez a afectarnos, pero no es un destino inevitable. Personalmente he conocido a varios(as) longevos(as) con más de cien años de edad que son brillantes, lúcidos(as) y con gran sentido del humor. En algunos casos -una minoríapuede atribuirse esta vejez exitosa a una lotería genética bendita. La gran mayoría lo ha logrado, a sabiendas o no, con una combinación de genética favorable, actitudes, conductas y estilo de vida, que les permitió evitar esta temible enfermedad de la vejez.

El profesor alemán Alois Alzheimer describió hace un siglo, en 1906, el primer caso clínico y la autopsia con los cambios característicos en el cerebro de una paciente, Auguste D., quien murió a los 56 años con demencia pre senil, a partir de entonces demencia tipo Alzheimer. Este fue un típico caso de causa genética, hereditaria, prácticamente inevitable por ahora, pero que representa apenas una minoría, cerca de un diez por ciento de todos los casos. La gran mayoría de las personas con Alzheimer son mayores de 65 años, y sobre todo, en la octava década de la vida.

Aunque hay un componente genético muy fuerte (tres genes identificados) en los afectados antes de la tercera edad, otros genes como el APOE4, que cuadriplica el riesgo, continúan jugando un papel en los mayores. Pero en general, la influencia genética en los ancianos es menos intensa y en algunos casos similar a la de otros factores más bien relacionados con el estilo de vida y otras enfermedades asociadas, principalmente las cardiovasculares y sus diversos factores de riesgo. Los doctores Jorge Huete y Elisa Sentis ampliaron sobre los aspectos genéticos en la revista Encuentro No.78, 2007. 
La demencia tipo Alzheimer comparte su espacio con otro tipo de demencia, la vascular, que es el resultado de las enfermedades cardiovasculares, circulatorias y cerebrovasculares, como los "derrames cerebrales", manifestados clínicamente, o que no se diagnosticaron antes por no haber producido síntomas.

Hoy en día, con la ayuda de tests clínicos de fácil aplicación, y de métodos de imágenes como la resonancia magnética, la tomografía y el ultrasonido, entre otros, se puede identificar a los pacientes afectados o en riesgo y tomar las medidas necesarias de prevención y tratamiento.

Estos dos tipos de demencia se potencian entre sí, y ambos son fuertemente influenciados por los factores de riesgo cardiovascular, como la hipertensión arterial, el colesterol, el tabaco y la diabetes, entre otros, de modo que es fundamental identificar estos factores, prevenirlos y tratarlos.

Las enfermedades circulatorias y degenerativas del corazón y del cerebro son las principales causas de muerte en el mundo actual. En la prevención y tratamiento de los infartos cardíacos se han logrado grandes avances. Pero los daños al cerebro son mayormente irreversibles y afectan no solamente a los ejecutivos que toman importantes decisiones a diario, sino a todo ser humano que pierde su memoria, sus facultades y su personalidad, causando gran angustia personal y a sus familiares. De modo que la prevención en este caso es fundamental.

Todos nos quejamos ocasionalmente de "olvidos", que mayormente se deben a distracciones, atender varias cosas a la vez (incluyendo el teléfono celular), estrés, ansiedad o depresión, todos factores corregibles o tratables. Pero cuando los que nos rodean empiezan a notar alteraciones en nuestra memoria y comportamiento, entonces no hay tiempo que perder para pedir ayuda especializada.

Aunque falta mucho por aprender, se sabe que existe una fuerte asociación entra la enfermedad de Alzheimer y la edad, la historia familiar, el gen APOE4, traumas craneales, depresión, hipertensión arterial, diabetes, colesterol elevado, arritmias cardíacas como la fibrilación auricular, coágulos o émbolos cerebrales, tabaquismo, alcoholismo (aunque un poco de vino puede ser protector), algunas deficiencias vitamínicas como B12 y ácido fólico, algunas reacciones inflamatorias (los antiinflamatorios no esteroides y los inhibidores del llamado TNF alfa pueden ser beneficiosos), exceso de ingestión calórica o dieta rica en carnes rojas, baja escolaridad y poca actividad de aprendizaje, así como poca actividad física.

La dieta mediterránea, rica en ensaladas, vegetales, frutas, nueces, pescado, aceite de oliva y algo de vino, así como el ejercicio y evitar el exceso de calorías en forma de gaseosas, dulces o grasas animales, entre otros, son claramente beneficiosos. En un estudio reciente de cinco años, una de cada catorce personas evitó la demencia con sólo estas medidas.

Recordemos que "lo que es bueno para el corazón es bueno para el cerebro". Entonces es ahora que podemos iniciar o reforzar un estilo de vida saludable para el cerebro. Éste 
consiste en:

1.- Mantener su cerebro activo en aprendizaje y creatividad.

2.- Comer y beber saludablemente.

3.- Mantenerse activo físicamente.

4.- Tratar con su médico la hipertensión arterial, el colesterol, la diabetes, la obesidad, la depresión y la ansiedad intensa o crónica.

5.- No fumar y evitar el exceso de bebidas alcohólicas.

6.- Participar en actividades sociales.

7.- Proteger su cerebro de golpes y traumas.

Dado el alto costo económico y humano de tratar la demencia, tanto de tipo Alzheimer como vascular, y puesto que los presupuestos de salud pública son muy limitados, en diferentes países se han creado fundaciones para la educación, prevención y apoyo de los afectados por estas enfermedades, como la Fundación de Alzheimer de Nicaragua.

Debemos pues enfatizar la educación y la prevención, incluyendo el tratamiento oportuno de los factores de riesgo cardiovascular y los otros mencionados en las siete acciones preventivas recomendadas anteriormente. Así podrá reducir el riesgo de esta catástrofe llamada demencia. También podrá apreciar más, y temerle menos, a Alois Alzheimer. 